\title{
Estudos sobre Acionamento e Controle de Máquinas de Relutância Variável
}

\author{
Igor D. Loss*, Marcelo V. De Paula, Thiago A. Lopes, Tárcio A. S. Barros
}

\section{Resumo}

Esse projeto tem por objetivo desenvolver estudos relacionados aos métodos de acionamento e controle velocidade de máquinas de relutância variável (MRV) em seu modo de operação como motor, para os mais diversos tipos de aplicação, através do estudo das simulações de seu modelo matemático em ambiente de software.

\section{Palavras-chave:}

Motor de relutância variável, histerese de corrente, pulso único de tensão.

\section{Introdução}

O projeto de iniciação científica em questão aborda o estudo referente a máquinas de relutância variável (MRV), sendo que um dos primeiros modelos foi construído por volta de 1830 . Em razão da complexidade de seu acionamento, os estudos relacionados a esse tema só foram retomados e difundidos graças ao desenvolvimento da eletrônica de potência nas últimas décadas'.

O motor de relutância variável, abordado nesse projeto, é constituído por um rotor magnético móvel e um estator, por onde as fases da máquina são energizadas. O torque é gerado com a tendência de alinhamento entre os polos do rotor e do estator. Com o aumento da indutância no estator, é gerado o movimento rotativo3.

Devido a sua simplicidade, em termos de construção, os motores de relutância apresentam maior eficiência energética, robustez e baixo custo ${ }^{2}$. Além disso operam por uma grande faixa de velocidades, podendo ser utilizados em aplicações que exijam velocidades variáveis, altas e baixas como, por exemplo, em carros elétricos, turbinas eólicas e sistemas de ventilação4.

Dessa forma, desenvolveu-se esse estudo objetivando-se ampliar o entendimento acerca do princípio de funcionamento, as formas de acionamento e controle de velocidade do motor de relutância. Buscando, assim, promover sua disseminação, uma vez que possui vantagens em relação aos motores já utilizados.

\section{Resultados e Discussão}

O estudo consiste em desenvolver um modelo dinâmico reproduzido em software (Matlab/Simulink) a fim de emular o comportamento real da MRV. Para isso, foi desenvolvido um modelo matemático para as equações de tensão em cada fase e torque. A partir destas, é possível extrair informações como torque, velocidade instantânea, corrente em cada fase e posição angular rotor.

A partir de uma velocidade de referência e ângulo de acionamento das fases, o controlador PI é utilizado a fim de processar e corrigir o erro gerado para a velocidade referência e a instantânea, de forma a promover o controle da velocidade.

A equação de tensão é composta por três termos, onde dois deles são associados à queda de tensão referentes às impedâncias nos enrolamentos do estator e outro que é a força contra- eletromotriz (FCM) ${ }^{2}$. Com o aumento da velocidade, quando a FCM se torna o termo predominante da equação, a velocidade de base é atingida ${ }^{1}$.

No modelo em questão, são adotados dois tipos de acionamentos: histerese de corrente para velocidades abaixo da velocidade de base e pulso único de tensão para velocidades acima desta.

A Figura 1 a seguir retrata os resultados da simulação computacional realizada em uma MRV 12/8 polos operando em modo motor com inversão de rotação e torque de carga em sentido contrário ao movimento. A máquina funciona em histerese até a velocidade de 100 $\mathrm{rad} / \mathrm{s}$ e passa a operar em pulso único ao atingir acima desta, em ambos sentidos.

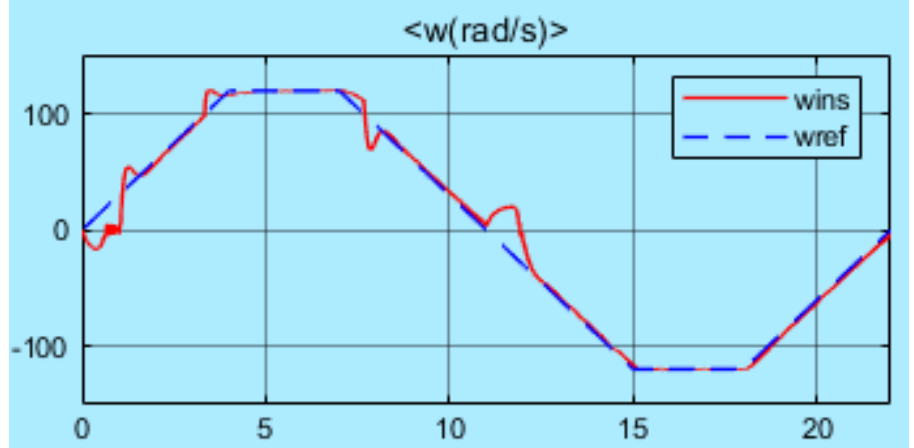

Figura 1: Perfil de velocidade instantânea no tempo

$$
\text { Conclusões }
$$

Portanto, com a realização deste trabalho foi possível conhecer mais sobre as características de funcionamento de uma MRV bem como desenvolver um modelo computacional que retrata o comportamento esperado para diferentes níveis de velocidade. Assim, os resultados obtidos foram muito satisfatórios indicando dessa forma, a confiabilidade do modelo matemático idealizado no início do projeto. Isso sem dúvida é de grande importância para o avanço dos estudos, uma vez que a simulação além de possibilitar rapidez, reduz muito o risco de haver erros e custos adicionais com os testes em bancada.

\section{Agradecimentos}

\section{$\mathrm{PIBIC} / \mathrm{CNPq}$ - Centro Nacional de Pesquisa}

\footnotetext{
1 T. J. E. Miller. "Eletronic Control of Switched Reluctance Machines." Newnes Power Engineering Series. (2001).

2 Krishnan, "Switched Reluctance Motor Drives - Modeling, Simulation, Analisys, Design, and Applications", CRC PRESS, Industrial electronics series, 2001

T. A. S Barros (2012). Uma contribuição ao Estudo e Desenvolvimento deTécnicas de Controle de Potência Ativa e Reativa do Gerador de Relutância Variável para Aplicações em Sistemas de geração Eólica de Pequena Potência, FEEC/UNICAMP, Campinas, SP.

4 V. Petrus, Switched Reluctance Motor for Electric Vehicle Propulsion Comparative, Numerical and Experimental Study of Control Schemes, Ph.D. dissertation, 2012.
} 